\title{
Article \\ Advanced Platelet-Rich Fibrin as a Therapeutic Option in the Treatment of Dry Socket: Literature Review and Case Series
}

\author{
Gaetano Marenzi, Roberta Gasparro, Mauro Mariniello, Gilberto Sammartino *D, Claudia Capone \\ and Alessandro Espedito di Lauro
}

Citation: Marenzi, G.; Gasparro, R.; Mariniello, M.; Sammartino, G.;

Capone, C.; di Lauro, A.E. Advanced Platelet-Rich Fibrin as a Therapeutic Option in the Treatment of Dry Socket: Literature Review and Case Series. Appl. Sci. 2021, 11, 9474. https://doi.org/10.3390/app11209474

Academic Editor: Bruno Chrcanovic

Received: 21 September 2021

Accepted: 6 October 2021

Published: 12 October 2021

Publisher's Note: MDPI stays neutral with regard to jurisdictional claims in published maps and institutional affiliations.

Copyright: (c) 2021 by the authors. Licensee MDPI, Basel, Switzerland. This article is an open access article distributed under the terms and conditions of the Creative Commons Attribution (CC BY) license (https:/ / creativecommons.org/licenses/by/ $4.0 /)$.
Department of Neuroscience, Reproductive Science and Dentistry, University of Naples Federico II, 80131 Naples, Italy; gaetano.marenzi@unina.it (G.M.); roberta.gasparro@unina.it (R.G.); mauro.mariniello@gmail.com (M.M.); caponeclaudia90@gmail.com (C.C.); alessandroespedito.dilauro@unina.it (A.E.d.L.)

* Correspondence: gilberto.sammartino@unina.it; Tel.: +39-081-746-2118
Abstract: Alveolar osteitis (AO) is one of the complications that occur after tooth extraction. The aim of this study has been to evaluate the efficacy of Advanced Platelet-rich Fibrin (A-PRF) in the management of pain and the acceleration of wound healing in the treatment of AO. Consecutive patients who were diagnosed with AO, recruited from patients referred to the Oral Surgery Department of the University of Naples Federico II, were enrolled. After local anesthesia, the dry socket was curetted and irrigated with saline. The Platelet-rich Fibrin (PRF) clot was placed in the socket and then covered with an A-PRF membrane. Clinical parameters, such as the degree of pain and rate of granulation tissue (GT) formation, were measured before treatment and after 1, 3, 7, 14, and 21 days. The Friedman test for dependent samples was used to detect the treatment and time effect. Four patients with established AO were included. On all the examination days, the post-operative recovery was uneventful. The pain scores progressively reduced, from an average of 8.5 before treatment to 0.25 on the third day, and the GT formation improved over time. The use of A-PRF in the treatment of AO significantly reduced the pain level and enhanced the wound-healing process.

Keywords: case series; alveolar osteitis; dry socket; platelet-rich fibrin; vasoconstrictor; A-PRF membrane; PRF

\section{Introduction}

Dry socket, or alveolar osteitis (AO), originally described by Crawford in 1896, is one of the complications that occur after tooth extraction [1]. It is accompanied by a partially or totally disintegrated blood clot resulting in the exposure of the alveolar socket walls, associated with acute and intense pain, without any sign of inflammation or infection and with or without halitosis [2,3]. The incidence is estimated at between 5 and 30\% [4] with a greater rate occurring after the extraction of the mandibular third molars [5]. AO is still poorly understood and different factors have been reported as being predisposing factors for the development of dry socket, relating either to the patient, such as age, gender, smoking habit, or the use of oral contraceptives, or to a traumatic surgical extraction or previous infection [6-8]. Additionally, the microbiota of patients who develop AO probably play an important role in the pathogenesis of this complication [9]. Although the underlying etiology remains unclear, dry socket is related to an alteration in the formation of the blood clot. Indeed, according to Birn [10], dry sockets show increased fibrinolytic activity and activation of plasminogen in the plasmin resulting in an early dissolution of the blood clot, which leaves the bony wall exposed to the oral cavity.

Autogenous Platelet Concentrates (APCs) are blood-derived products and are considered the natural evolution of the fibrin sealant widely used in oral and maxillofacial surgery [11-13]. APCs are prepared from the patient's own blood, which is centrifuged producing a fibrin meshwork, where the platelets, cytokines, growth factors, and cells are 
embedded [14,15]. Clinical studies and systematic reviews have reported an advantage in the topical use of APCs in order to support hemostasis and promote bone graft healing [16]. Alpha granules are the main platelet components that contribute to wound healing by means of growth factors (i.e., "Platelet-Derived Growth Factors" (PDGF), "Transforming Growth Factors $\beta 1$ and $\beta 2$ " (TGF $\beta 1-T G F \beta 2)$, "Vascular Endothelial Growth Factor" (VEGF), "Insulin-like Growth Factor-1" (IGF-1), and "Epidermal Growth Factor (EGF)) [17]. Platelet-rich Fibrin (PRF) represents the second generation of APCs [18]. During the PRF preparation, the polymerization of fibrinogen into fibrin occurs slowly, naturally, and progressively in the presence of physiological thrombin, resulting in a strong natural fibrin meshwork, composed of a tetra molecular structure. This meshwork is able to entrap the activated platelets, leukocytes, and circulating/intrinsic cytokines, favoring their slow release (over seven days) $[19,20]$.

In the recent past, different methods have been proposed for the prevention and management of dry socket. Medicated dressings, phototherapy, topical anesthetic gel, Alvogyl, etc., [20] were used mainly for pain relief, but at present, no current evidencebased consensus exists on which modality should be used as the gold standard in the treatment of $\mathrm{AO}$ to obtain socket healing. The literature evaluating the effect of PRF on alveolar osteitis is mainly focused on the prevention of this complication, especially after the extraction of the lower third molar [21], where the incidence of AO is higher. Moreover, different platelet concentrates have been used for the management of $\mathrm{AO}$, such as the concentrated growth factor and platelet-rich in growth factors, without giving definitive recommendations [22-24]. PRF can act as a stable blood clot for neovascularization and tissue healing. The aim of this study has been to evaluate the efficacy of Advanced PlateletRich Fibrin (A-PRF) in the management of pain and the acceleration of wound healing in the treatment of dry socket.

\section{Materials and Methods}

\subsection{Study Design and Patient Selection}

This study was designed as a prospective case series. Four patients ( 3 females, 1 male-mean age 34.7 years) who had been diagnosed with AO, recruited from patients referred to the Oral Surgery Department of the University of Naples Federico II between June and December 2020, were enrolled. The inclusion criteria were as follows: Aged $>18$ years, without any systemic disease, and with an untreated case of $\mathrm{AO}$, diagnosed within three days after the extraction. In accordance with Blum et al. [12], the diagnostic criteria consisted of the presence of increasing post-operative pain severity within three days after surgery and a total or partial breakdown of the blood clot in the socket. The exclusion criteria were as follows: The use of any medications that may interfere with the healing process (e.g., corticosteroids), a case of third molar $\mathrm{AO}$, and the use of more than one analgesic drug in post-operative recovery. Information about the modality of extraction and type of anesthetic used was obtained by contacting the patient's dentist by phone. The procedures were explained, and informed consent was obtained from all the participants. All the procedures performed in the study were carried out in accordance with the ethical standards of the institutional research committee and the 1964 Declaration of Helsinki and were approved by the Ethical Committee (Protocol number 56/15). The case series was reported in line with the PROCESS Guidelines [25].

\subsection{Clinical Measurements}

All the measurements were carried out by a single masked examiner, who did not perform the surgery, before (T0) treatment and on the 1st (T1), 3rd (T2), 7th (T3), 14th (T4), and 21st (T5) days post-treatment. The level of pain was assessed using a 10-point visual analogic scale, with a score of " 0 " equal to "no pain" and " 10 " equal to "very severe pain". The rate of granulation tissue (GT) formation was clinically evaluated and recorded as follows. A complete absence of GT was recorded as 0 . The formation of GT over one-quarter or less of the socket was recorded as 1 , over half of the socket as 2 , over 
three-quarters as 3, while a complete covering of granulation over the whole socket was recorded as 4 [26].

\subsection{Preparation of $A-P R F$}

The A-PRF was prepared according to the protocol of Choukroun et al. as follows: $40 \mathrm{~mL}$ of blood from each patient was collected in 4 dry glass tubes of $10 \mathrm{~mL}$ each. The blood collection was performed as quickly as possible, and the tubes were immediately centrifuged for $14-\mathrm{min}$ at $100 \times g$ using a dedicated centrifuge (PC-02, Process for PRF, Nice, France) at room temperature. Following centrifugation, three layers were distinguished in the tube: The upper layer consisted of Platelet Pure Plasma (PPP), the middle layer of a PRF fibrin clot, and the lower layer of red blood cells (RBCs). The A-PRF fibrin clot was removed from the tube using sterile tweezers, separated from the red blood cells with scissors, and then placed in a sterile cup. Furthermore, 1-2 $\mathrm{mm}$ of the most superficial part of the RBC layer, called the buffy coat, was collected as it contains many growth factors. Two A-PRFs were used in the socket as clots and two A-PRFs were transformed into membranes through a dedicated box and used to cover the sockets.

\subsection{Surgical Procedure}

After local anesthesia, the dry socket was curetted and irrigated with saline. A new bleeding socket was created following curettage, and gentle saline irrigation helped to debride the necrotic debris. The PRF clot was placed in the socket and then covered with an A-PRF membrane. A resorbable suture was placed to stabilize the A-PRF membranes. There were no additional dressings or medications inserted in the socket. To control the bias, a single operator treated all the patients.

\subsection{Post-Operative Recommendations}

The patients were given antibiotics (amoxicillin and clavulanic acid every $12 \mathrm{~h}$ for 8 days). Plaque control of the surgically treated area was maintained by rinsing with $0.12 \%$ chlorhexidine gluconate every $12 \mathrm{~h}$ for 10 days. Moreover, all the patients were asked, if possible, to not take any analgesic pain or anti-inflammatory drugs in the post-operative period to assess the real antinociceptive role of PRF. The sutures were removed 10 days after application. A cold and soft diet and appropriate oral hygiene were recommended for two weeks.

\subsection{Statistical Analysis}

The GT formation measurements were performed in triplicate and averaged to reduce any error. The data were calculated using the mean value \pm standard deviation. On account of the small sample size, the Friedman test for multiple dependent samples was used to detect the treatment and time effect. The statistical analysis was performed using Statistical Package for Social Sciences Software (IBM Corp. Released 2012. IBM SPSS Statistics for Windows, Version 21.0. Armonk, NY, USA: IBM Corp). $p<0.05$ was set as the level for statistical significance.

\section{Results}

Over a six-month period, four patients (one male and three female) with established $\mathrm{AO}$ were included in the study. The mean age was 34.7 years. All the participants were periodontically and generally healthy, did not take drugs and had no medical contraindications for surgery, and three out of four were non-smokers. All the patients presented with an established AO involving, respectively, two upper first premolars, one per patient, one lower second premolar, and one lower first molar. Oral hygiene was good in all cases. The patient characteristics are summarized in Table 1. 
Table 1. Patient demography and clinical characteristics.

\begin{tabular}{|c|c|c|c|c|}
\hline & Gender; Age & AO Site & Type of Anesthesia & Anesthetic Used \\
\hline Patient 1 & $\mathrm{~F} ; 26$ & 1st upper premolar & local & $\begin{array}{l}\text { mepivacaine } 2 \% \text { with } \\
1: 100,000 \text { epinephrine }\end{array}$ \\
\hline Patient 2 & $\mathrm{~F} ; 40$ & 1st upper premolar & local & $\begin{array}{l}\text { mepivacaine } 2 \% \text { with } \\
1: 200,000 \text { epinephrine }\end{array}$ \\
\hline Patient 3 & $\mathrm{~F} ; 38$ & 2nd lower premolar & local & $\begin{array}{l}\text { mepivacaine } 2 \% \text { with } \\
1: 100,000 \text { epinephrine }\end{array}$ \\
\hline Patient 4 & M; 35 & 1st lower molar & Local and intraligamentary & $4 \%$ articaine with $1: 100,000$ epinephrine \\
\hline
\end{tabular}

F: Female; M: Male; AO: Alveolar osteitis.

On all the examination days, the post-operative recovery was uneventful and none of the patients were taking any analgesic drugs. No surgical sites showed any signs of infection or mucositis. The descriptive statistics for the clinical parameters measured at $\mathrm{T} 0$, T1, T2, T3, T4, and T5 are shown in Table 2.

Table 2. Descriptive statistics.

\begin{tabular}{cccccccc}
\hline Mean & T0 & T1 & T2 & T3 & T4 & T5 \\
\hline VAS score & 8.5 & 3.5 & 0.25 & 0 & 0 & 0 \\
GT formation & 0 & 0.25 & 1.75 & 3.25 & 4 & 4 \\
\hline
\end{tabular}

VAS: Visual analogic scale; GT: Granulation tissue; (T0) before treatment; (T1) 1st day; (T2) 2nd day; (T3) 3rd day; (T4) 4th day; and (T5) 5th day after treatment.

The pain scores statistically decrease from an average of 8.5 pre-operatively to 3.5 on the first day after PRF application, to 0.25 on the third day, and subsequently to 0 at the following time points (Friedman test, $p=0.002$ ). The GT formation within the healing socket progressively improved statistically from an average of 0 before treatment to 0.25 on the first day, 1.75 on the third day, 3.25 on the seventh day, and 4 on the fourteenth and twenty-first days after the treatment (Friedman test, $p=0.002$ ).

\section{Discussion}

Dry socket is a frequent complication in exodontia, often associated with the extraction of third molars. Many risk factors are involved, such as traumatic tooth extraction, oral contraceptive intake, smoking, poor hygiene, and the use of a vasoconstrictor in local anesthesia [3,27].

In our study, the patients were referred from four different dentists and the degree of traumatization cannot be objectively recorded. The role of a vasoconstrictor in local anesthesia in the etiology of $\mathrm{AO}$ is not fully established. Lehner found that the $\mathrm{AO}$ frequency increases with infiltration anesthesia because the temporary ischemia leads to a poor supply [28]. In contrast, other studies have shown that this ischemia lasts for a short time and is followed by reactive hyperemia [29], which allows blood clot formation and stabilization. However, in our study, in one case, the dentist performed intraligamentary anesthesia with a solution of $4 \%$ articaine with epinephrine, 1:100,000, for the extraction of a lower first molar, without performing the inferior alveolar nerve block. The intraligamentary injection involves deposition of the local anesthetic solution in the periodontal ligament space around the root. The excessive pressure of the injection, using a Citoject syringe, the use of a vasoconstrictor, and the need for a second infiltration, as reported by the patient's dentist, probably altered the formation of the blood clot, inducing AO.

The tissue regeneration or repair process requires a harmonious reaction of various types of cells, including immune cells (neutrophils, macrophages, and lymphocytes), epithelial cells, fibroblasts, and stem cells. The rationale for the use of hemocomponents in the treatment of this condition is that it accelerates the healing of soft and hard tissues by increasing the concentration of growth factors [30,31]. Platelet growth factors serve as messengers to regulate a well-orchestrated and complex series of events involving cell-cell 
and cell-matrix interactions and to promote the proliferation of cells at the wound site. Furthermore, platelet concentrates seem to increase the migration and proliferation of osteoblasts and have a positive effect on stem cells and periodontal healing [32]. Additionally, it has been reported that the use of PRF reduces post-operative complications as well as the incidence of $\mathrm{AO}$, especially following third-molar surgery [33-35]. A summary of the substantial literature on the topic is reported in Table 3.

Table 3. Summary of literature review.

\begin{tabular}{|c|c|c|c|c|c|}
\hline & N Patients & AO Site & Type of APC Used & Pain & Wound Healing \\
\hline Kamal et al. [23] & 40 & NR & CGF & $\begin{array}{l}\text { Reduction of pain on } 4 \text { th } \\
\text { and } 7 \text { th post-op day }\end{array}$ & $\begin{array}{l}\text { GT formation by } \\
\text { day } 4\end{array}$ \\
\hline Kamal et al. [24] & 15 & NR & CGF & $\begin{array}{l}\text { Reduction of pain on } 2 \text { nd } \\
\text { and } 7 \text { th post-op day }\end{array}$ & $\begin{array}{l}\text { GT formation by } \\
\text { day } 4\end{array}$ \\
\hline Chakravarthi [33] & 10 & Any tooth & PRF & $\begin{array}{l}\text { Reduction of pain by the } \\
\text { 1st post-op day }\end{array}$ & NR \\
\hline Sharma et al. [34] & 100 & $\begin{array}{l}\text { Mandibular and } \\
\text { maxillary molars }\end{array}$ & PRF & $\begin{array}{l}\text { Reduction of pain on 3rd } \\
\text { and 7th post-op day }\end{array}$ & $\begin{array}{l}\text { Better WH by the } \\
\text { end of } 2^{\text {nd }} \text { week }\end{array}$ \\
\hline Yuce et al. [35] & 20 & Third molars & A-PRF & $\begin{array}{l}\text { Reduction of pain by the } \\
\text { 1st post-op day }\end{array}$ & $\begin{array}{l}\text { Better Soft tissue } \\
\text { healing by day } 7\end{array}$ \\
\hline
\end{tabular}

APC: Autogenous Platelet Concentrates; WH: Wound healing; NR: Not reported; CGF: Concentrated growth factor; GT: Granulation tissue.

In this study, we have used PRF because its strong fibrin architecture, composed of thin fibers with micropores, serves as a scaffold and support for blood clots. The fibrin matrix slowly releases growth factors until seven days post-operatively, which favor cell migration and differentiation. [19] PRF is an important reservoir of growth factors that promote angiogenesis, above all VEGF, but also PDGF and TGF- $\beta$. In our study, we chose A-PRF because it releases VEGF at higher levels compared to L-PRF (Leukocyte-Plateletrich Fibrin). [14] VEGF is largely produced by the leukocytes [31] and is crucial for the promotion of angiogenesis during tissue repair. Indeed, reduced expression and rapid proteolytic degradation of VEGF are considered partially responsible for poor wound healing, for example in diabetic wounds, because these effects result in poor angiogenesis during GT formation. Thus, the angiogenesis induced by VEGF and other factors represents a significant step in the treatment of non-healing wounds and other ischemic processes, where clotting has failed to induce the healing, as in AO. The acceleration of wound healing in our study is confirmed by the fact that the GT appeared clearly after only three days after treatment (mean 3.25).

Previous studies have indicated that bacteria may play an important role in the pathogenesis of $\mathrm{AO}$ [9]. In our study, the post-operative recovery was uneventful, and no surgical sites showed any signs of infection or mucositis. In addition to their tissue-forming and proliferative effects, growth factors released by A-PRF exhibit a chemotactic effect that causes the migration of macrophages and neutrophils, adding an antimicrobial component to the wound site.

All the patients in our sample suffering from dry socket experienced severe pain with a median VAS pain score of 8.5 on the day of presentation. Indeed, it is a well-established fact that the pain associated with $\mathrm{AO}$ is severe, continuing throughout the night and responding poorly to analgesics [36]. The pain for all the patients decreased statistically in the first day. None of the patients needed to take analgesic drugs and therefore we can assume a predominant role of PRF in the reduction of pain. This result is in accordance with other studies supporting the antinociceptive role of platelet concentrates [30-32].

Despite the encouraging results obtained, several limitations should be acknowledged. The nature of the study (a case series) and the lack of a control group may compromise the validity of the final results. The low sample size is due to the infrequent diagnosis of "true" AO, which is often erroneously confused with socket infection accompanied by pain. In addition, the prospective nature of the study makes it difficult to perform a sample size calculation and control group. However, the only comparison that we can make is 
with previous treatment of AO performed in our department with the use of debridement and saline solution washing. Although the healing was obtained in every case over the follow up-period, the time for healing was longer, and the reduction of pain was less rapid. However, further controlled studies with a larger sample would be required in the future in order to obtain more reliable results.

\section{Conclusions}

Within the limitations of this non-controlled case series study, the use of A-PRF in the treatment of alveolar osteitis may significantly reduce pain levels and also improve the wound-healing process.

Author Contributions: Conceptualization, G.M. and G.S.; methodology, R.G.; software, C.C.; validation, G.S., G.M., and A.E.d.L.; formal analysis, M.M.; investigation, C.C.; resources, M.M.; data curation, M.M.; writing — original draft preparation, R.G.; writing—review and editing, G.S.; visualization, A.E.d.L.; supervision, G.S. All authors have read and agreed to the published version of the manuscript.

Funding: This research received no external funding.

Institutional Review Board Statement: The study was conducted according to the guidelines of the Declaration of Helsinki. Ethical review and approval were waived for this study, due to that the procedure used falls within ordinary clinical care.

Informed Consent Statement: Informed consent was obtained from all subjects involved in the study. Written informed consent has been obtained from the patients to publish this paper.

Data Availability Statement: The patients' data used to support the findings of this study have not been made available for ethical concerns and patient privacy.

Conflicts of Interest: The authors declare no conflict of interest.

\section{References}

1. Crawford, J.Y. Dry socket. Dent. Cosm. 1896, 38, 929-931.

2. Blum, I.R. Contemporary views on dry socket (alveolar osteitis): A clinical appraisal of standardization, aetiopathogenesis and management: A critical review. Int. J. Oral Maxillofac. Surg. 2002, 31, 309-317. [CrossRef] [PubMed]

3. Chow, O.; Wang, R.; Ku, D.; Huang, W. Alveolar Osteitis: A Review of Current Concepts. J. Oral Maxillofac. Surg. 2020, 78, 1288-1296. [CrossRef]

4. Aguilar-Durán, L.; Figueiredo, R.; Seminago, R.; Roig, F.J.; Llorens, C.; Valmaseda-Castellón, E. A metagenomic study of patients with alveolar osteitis after tooth extraction. A preliminary case-control study. Clin. Oral Investig. 2019, 23, 4163-4172. [CrossRef] [PubMed]

5. Øyri, H.; Jensen, J.L.; Barkvoll, P.; Jonsdottir, O.H.; Reseland, J.; Bjørnland, T. Incidence of alveolar osteitis after mandibular third molar surgery. Can inflammatory cytokines be identified locally? Acta Odontol. Scand. 2020, 79, 205-211. [CrossRef] [PubMed]

6. Almeida, L.E.; Pierce, S.; Klar, K.; Sherman, K. Effects of oral contraceptives on the prevalence of alveolar osteitis after mandibular third molar surgery: A retrospective study. Int. J. Oral Maxillofac. Surg. 2016, 45, 1299-1302. [CrossRef] [PubMed]

7. Eshghpour, M.; Rezaei, N.M.; Nejat, A. Effect of menstrual cycle on frequency of alveolar osteitis in women undergoing surgical removal of mandibular third molar: A single-blind randomized clinical trial. J. Oral Maxillofac. Surg. 2013, 71, 1484-1489. [CrossRef] [PubMed]

8. Heng, C.K.; Badner, V.M.; Clemens, D.L.; Mercer, L.T.; Mercer, D.W. The relationship of cigarette smoking to postoperative complications from dental extractions among female inmates. Oral Surg. Oral Med. Oral Pathol. Oral Radiol. Endod. 2007, 104, 757-762. [CrossRef] [PubMed]

9. Riba-Terés, N.; Jorba-García, A.; Toledano-Serrabona, J.; Aguilar-Durán, L.; Figueiredo, R.; Valmaseda-Castellón, E. Microbiota of alveolar osteitis after permanent tooth extractions: A systematic review. J. Stomatol. Oral Maxillofac. Surg. 2021, 122, $173-181$. [CrossRef]

10. Birn, H. Fibrinolytic activity in "dry socket". Acta Odontol Scand. 1970, 28, 37-58. [CrossRef]

11. Marx, R.E.; Carlson, E.R.; Eichstaedt, R.M.; Schimmele, S.R.; Strauss, J.E.; Georgeff, K.R. Platelet-rich plasma: Growth factor enhancement for bone grafts. Oral Surg. Oral Med. Oral Pathol. Oral Radiol. Endod. 1998, 85, 638-646. [CrossRef]

12. Miron, R.J.; Zucchelli, G.; Pikos, M.A.; Salama, M.; Lee, S.; Guillemette, V.; Fujioka-Kobayashi, M.; Bishara, M.; Zhang, Y.; Wang, H.L.; et al. Use of platelet-rich fibrin in regenerative dentistry: A systematic review. Clin. Oral Investig. 2017, 21, 1913-1927. [CrossRef] 
13. Gasparro, R.; Qorri, E.; Valletta, A.; Masucci, M.; Sammartino, P.; Amato, A.; Marenzi, G. Non-Transfusional Hemocomponents: From Biology to the Clinic-A Literature Review. Bioengineering 2018, 5, 27. [CrossRef]

14. Cabaro, S.; D’Esposito, V.; Gasparro, R.; Borriello, F.; Granata, F.; Mosca, G.; Passaretti, F.; Sammartino, J.C.; Beguinot, F.; Sammartino, G.; et al. White cell and platelet content affects the release of bioactive factors in different blood-derived scaffolds. Platelets 2018, 29, 463-467. [CrossRef] [PubMed]

15. Kobayashi, E.; Flückiger, L.; Fujioka-Kobayashi, M.; Sawada, K.; Sculean, A.; Schaller, B.; Miron, R.J. Comparative release of growth factors from PRP, PRF, and advanced-PRF. Clin. Oral Investig. 2016, 20, 2353-2360. [CrossRef] [PubMed]

16. Marenzi, G.; Riccitiello, F.; Tia, M.; di Lauro, A.E.; Sammartino, G. Influence of Leukocyte- and Platelet-Rich Fibrin (L-PRF) in the Healing of Simple Postextraction Sockets: A Split-Mouth Study. Biomed. Res. Int. 2015, 2015, 369273. [CrossRef] [PubMed]

17. Fujioka-Kobayashi, M.; Katagiri, H.; Kono, M.; Schaller, B.; Zhang, Y.; Sculean, A.; Miron, R.J. Improved growth factor delivery and cellular activity using concentrated platelet-rich fibrin (C-PRF) when compared with traditional injectable (i-PRF) protocols. Clin. Oral Investig. 2020, 24, 4373-4383. [CrossRef]

18. Dohan, D.M.; Choukroun, J.; Diss, A.; Dohan, S.L.; Dohan, A.J.; Mouhyi, J.; Gogly, B. Platelet-rich fibrin (PRF): A secondgeneration platelet concentrate. Part I: Technological concepts and evolution. Oral Surg. Oral Med. Oral Pathol. Oral Radiol. Endod. 2006, 101, e37-e44. [CrossRef] [PubMed]

19. Dohan Ehrenfest, D.M.; de Peppo, G.M.; Doglioli, P.; Sammartino, G. Slow release of growth factors and thrombospondin-1 in Choukroun's platelet-rich fibrin (PRF): A gold standard to achieve for all surgical platelet concentrates technologies. Growth Factors 2009, 27, 63-69. [CrossRef] [PubMed]

20. Pietruszka, P.; Chruścicka, I.; Duś-Ilnicka, I.; Paradowska-Stolarz, A. PRP and PRF-Subgroups and Divisions When Used in Dentistry. J. Pers. Med. 2021, 11, 944. [CrossRef]

21. Zhu, J.; Zhang, S.; Yuan, X.; He, T.; Liu, H.; Wang, J.; Xu, B. Effect of platelet-rich fibrin on the control of alveolar osteitis, pain, trismus, soft tissue healing, and swelling following mandibular third molar surgery: An updated systematic review and meta-analysis. Int. J. Oral Maxillofac. Surg. 2021, 50, 398-460. [CrossRef] [PubMed]

22. Puidokas, T.; Kubilius, M.; Nomeika, D.; Januzis, G.; Skrodeniene, E. Comparative Analysis of Blood Clot, Plasma Rich in Growth Factors and Platelet-Rich Fibrin Resistance to Bacteria-Induced Fibrinolysis. Microorganisms 2019, 7, 328. [CrossRef]

23. Kamal, A.; Salman, B.; Abdul Razak, N.H.; Qabbani, A.A.; Samsudin, A.R. The Efficacy of Concentrated Growth Factor in the Healing of Alveolar Osteitis: A Clinical Study. Int. J. Dent. 2020, 2020, 9038629. [CrossRef] [PubMed]

24. Kamal, A.; Salman, B.; Razak, N.; Samsudin, A. A Comparative Clinical Study between Concentrated Growth Factor and Low-Level Laser Therapy in the Management of Dry Socket. Eur. J. Dent. 2020, 14, 613-620. [PubMed]

25. Agha, R.A.; Sohrabi, C.; Mathew, G.; Franchi, T.; Kerwan, A.; O’Neill, N.; PROCESS Group. The PROCESS 2020 Guideline: Updating Consensus Preferred Reporting Of Case Series in Surgery (PROCESS) Guidelines. Int. J. Surg. 2020, 84, 231-235. [CrossRef] [PubMed]

26. Kamal, A.; Salman, B.; Ar, N.H.; Samsudin, A.R. Management of dry socket with low-level laser therapy. Clin. Oral Investig. 2021, 25, 1029-1033. [CrossRef] [PubMed]

27. Kolokythas, A.; Olech, E.; Miloro, M. Alveolar osteitis: A comprehensive review of concepts and controversies. Int. J. Dent. 2010, 249073. [CrossRef]

28. Lehner, T. Analysis of one hundred cases of dry socket. Dent. Pract. Dent. Rec. 1958, 8, 275-279.

29. Tsirlis, A.T.; Iakovidis, D.P.; Parissis, N.A. Dry socket: Frequency of occurrence after intraligamentary anesthesia. Quintessence Int. 1992, 23, 575-577.

30. Gasparro, R.; Adamo, D.; Masucci, M.; Sammartino, G.; Mignogna, M.D. Use of injectable platelet-rich fibrin in the treatment of plasma cell mucositis of the oral cavity refractory to corticosteroid therapy: A case report. Dermatol. Ther. 2019, 32 , e13062. [CrossRef]

31. D’Esposito, V.; Lecce, M.; Marenzi, G.; Cabaro, S.; Ambrosio, M.R.; Sammartino, G.; Misso, S.; Migliaccio, T.; Liguoro, P.; Oriente, F.; et al. Platelet-rich plasma counteracts detrimental effect of high-glucose concentrations on mesenchymal stem cells from Bichat fat pad. J. Tissue Eng. Regen. Med. 2020, 14, 701-713. [CrossRef]

32. Gasparro, R.; Sammartino, G.; Mariniello, M.; di Lauro, A.E.; Spagnuolo, G.; Marenzi, G. Treatment of periodontal pockets at the distal aspect of mandibular second molar after surgical removal of impacted third molar and application of L-PRF: A split-mouth randomized clinical trial. Quintessence Int. 2020, 51, 204-211. [PubMed]

33. Chakravarthi, S. Platelet rich fibrin in the management of established dry socket. J. Korean Assoc. Oral Maxillofac. Surg. 2017, 43, 160-165. [CrossRef] [PubMed]

34. Sharma, A.; Aggarwal, N.; Rastogi, S.; Choudhury, R.; Tripathi, S. Effectiveness of platelet-rich fibrin in the management of pain and delayed wound healing associated with established alveolar osteitis (dry socket). Eur. J. Dent. 2017, 11, 508-513. [CrossRef] [PubMed]

35. Yüce, E.; Kömerik, N. Potential effects of advanced platelet rich fibrin as a wound-healing accelerator in the management of alveolar osteitis: A randomized clinical trial. Niger. J. Clin. Pract. 2019, 22, 1189-1195. [CrossRef]

36. Loffredo, S.; Staiano, R.I.; Granata, F.; Genovese, A.; Marone, G. Immune cells as a source and target of angiogenic and lymphangiogenic factors. Chem. Immunol. Allergy 2014, 99, 15-36. 